\title{
Silica (NPs) supported Fe (III) as a reusable heterogeneous catalyst for the one-pot synthesis of 1, 4-dihydropyridines under mild conditions
}

\author{
JAVAD SAFAEI-GHOMI*, ABOLFAZL ZIARATI and SAFURA ZAHEDI \\ Department of Organic Chemistry, Faculty of Chemistry, University of Kashan, Kashan, 51167, I R Iran \\ e-mail: safaei@kashanu.ac.ir
}

MS received 26 December 2011; revised 4 March 2012; accepted 10 April 2012

\begin{abstract}
A cheap and recyclable silica (NPs) supported Fe (III) was prepared as heterogeneous catalyst for the synthesis of various substituted 1,4-dihydropyridines via condensation of aldehydes with ethyl acetoacetate and ammonium acetate in ethanol. The products were separated from the catalyst simply by filtration and the catalyst could be recycled and reused for several times without noticeable decrease in the catalytic activity.
\end{abstract}

Keywords. Heterogeneous catalyst; 1,4-dihydropyridine; multi-component; nano silica; Hantzsch reaction.

\section{Introduction}

Current literature reveals that 1,4-dihydropyridines exhibit interesting pharmacological and biological properties. Thus, they have been used as calcium channel modulators for the treatment of cardiovascular disorders. ${ }^{1}$ The 1,4-DHPs may lead to other beneficial effects such as regression of left ventricular pressure and vascular hypertrophy, renal protection and antiatherogenic activity. ${ }^{2-4}$ Furthermore, the DHP skeleton is common in many bronchodilator, antiatherosclerotic, antitumour, antidiabetic, geroprotective and hepatoprotective agents. ${ }^{5,6}$ They also function as neuroprotectants, as antiplatelet treatment of aggregators and are important in Alzheimer's disease as antiischaemic agents. ${ }^{7}$ Among 1,4-DHPs, there are also examples of drug-resistance modifiers, ${ }^{8}$ antioxidants 9 and a drug for the treatment of urinary urge incontinence. In order to model and understand these biological properties and to develop new chemotherapeutic agents based upon the 1,4-DHP motif, considerable effort has been devoted to establish efficient and rapid methods for their synthesis (figure 1). ${ }^{10}$

Recently, a number of modified methods have been developed. ${ }^{11,12}$ Some procedures comprise the use of microwaves, ${ }^{13}$ ionic liquids, ${ }^{14}$ high temperatures at reflux, ${ }^{15} \mathrm{TMSCl}-\mathrm{NaI},{ }^{16} \mathrm{InCl}_{3},{ }^{17} \mathrm{I}_{2},{ }^{18} \mathrm{NaHSO}_{4} / \mathrm{SiO}_{2},{ }^{19}$ $\mathrm{HClO}_{4} / \mathrm{SiO}_{2},{ }^{20} \mathrm{CAN},{ }^{21} \mathrm{Na}-$ and Cs-Norit carbons, ${ }^{22}$ tetrabutylammonium hydrogen sulfate, ${ }^{23}$ fermenting Baker's yeast, ${ }^{24}$ organocatalysts ${ }^{25}$ and metal triflates. ${ }^{26}$ However, some of these methods suffer from the drawback of green chemistry such as prolonged reaction

*For correspondence times, low yields, toxicity and recovery and reusability of the catalyst. Therefore, introducing clean processes and utilizing eco-friendly and green catalysts which can be simply recycled at the end of reactions have been under permanent attention. The best known procedure for the preparation of symmetrical 1,4-DHPs is the classical Hantzch synthesis: a multicomponent condensation involving two molecules of $\beta$-ketoesters, one molecule of aldehyde and one molecule of ammonia. ${ }^{27}$ The demand for environmentally benign procedure with heterogeneous and reusable catalyst promoted us to develop a safe alternate method for the synthesis of 1,4-dihydropyridines in the presence of silica (NPs) supported Fe (III) (scheme 1).

\section{Experimental}

The products were isolated and characterized by physical and spectral data. ${ }^{1} \mathrm{H}$ NMR and ${ }^{13} \mathrm{C}$ NMR spectra were recorded on Bruker Avance- $400 \mathrm{MHz}$ spectrometers in the presence of tetramethylsilane as internal standard. The IR spectra were recorded on FT-IR Magna 550 apparatus using with $\mathrm{KBr}$ plates. Melting points were determined on Electro thermal 9200, and are not corrected. Silica (NPs) supported Fe (III) was obtained according to the method reported in the literature. Microscopic morphology of products was visualized by SEM (LEO 1455VP).

\subsection{Preparation of silica (NPs) supported Fe (III)}

In a $100 \mathrm{ml}$ flask, nano silica gel $(25 \mathrm{~g})$ and $\mathrm{FeCl}_{3} \cdot 6 \mathrm{H}_{2} \mathrm{O}$ (2 g) (8\% of the weight of $\left.\mathrm{SiO}_{2} \mathrm{NPs}\right)$ were vigorously 
<smiles>CC(=O)C1=C(C)NC(C)=C(C(=O)OC(C)(C)CN(C)CCC(c2ccccc2)c2ccccc2)C1c1cccc([N+](=O)[O-])c1</smiles>

Lercanidipine<smiles>CC(=O)C1=C(C)NC(C)=C(C(=O)O[C@H]2CCN(Cc3ccccc3)C2)[C@H]1c1cccc([N+](=O)[O-])c1</smiles>

Barnidipine Hydrochoride<smiles>CCOC(=O)C1=C(C)NC(C)=C(C(=O)OC)C1c1cccc(Cl)c1Cl</smiles>

Figure 1. The pharmaceutical compounds with DHP skeleton.<smiles>CCOC(=O)C1=C(C)NC(C)=C(C(=O)OCC)C1C(=O)OCC</smiles>

Scheme 1. Synthesis of 1,4-dihydropyridines on silica (NPs) supported Fe (III) under reflux conditions.

stirred under solvent-free conditions at room temperature for $24 \mathrm{~h}$ to achieve a homogeneous adsorption. The obtained powder was yellow and heated for $1 \mathrm{~h}$ at $100^{\circ} \mathrm{C}$ to activate the catalyst.

\subsection{Preparation of 1,4-dihydropyridine derivatives}

A mixture of aldehyde 1 ( $1 \mathrm{mmol})$, ethyl acetoacetate $2(2 \mathrm{mmol})$, ammonium acetate $3(2 \mathrm{mmol})$ and silica (NPs) supported Fe (III) $(0.6 \mathrm{~mol} \%)$ was heated at

Table 1. Reaction of $p$-nitrobenzaldehyde, ethyl acetoacetate and ammonium acetate in diverse catalytic conditions.

\begin{tabular}{llcc}
\hline Entry & Catalyst (mol\%) & Time (min) & Yield, ${ }^{\text {a } \%}$ \\
\hline 1 & none & 180 & 0 \\
2 & $\mathrm{FeCl}_{3}(10)$ & 150 & 41 \\
3 & $\mathrm{SiO}_{2} \mathrm{NPs}(10)$ & 130 & 27 \\
4 & $\mathrm{FeCl}_{3} / \mathrm{SiO}_{2}(10)$ & 100 & 75 \\
5 & $\mathrm{FeCl}_{3} / \mathrm{SiO}_{2} \mathrm{NPs}(0.8)$ & 20 & 93 \\
6 & $\mathrm{FeCl}_{3} / \mathrm{SiO}_{2} \mathrm{NPs}(0.6)$ & 20 & 94 \\
8 & $\mathrm{FeCl}_{3} / \mathrm{SiO}_{2} \mathrm{NPs}(0.5)$ & 20 & 90 \\
\hline
\end{tabular}

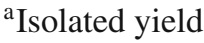

reflux in ethanol $(3 \mathrm{~mL})$. The reaction was monitored by TLC. After cooling to room temperature, the reaction mixture was filtered and the heterogeneous catalyst was recovered. The filtrate was poured into cold water and extracted with ethyl acetate. The organic layer was washed with brine and water and dried over $\mathrm{Na}_{2} \mathrm{SO}_{4}$. After evaporation of the solvent, the crude yellow products were purified by crystallization from ethanol to afford 1,4-dihydropyridines.

\subsection{Reusability of catalyst}

The recovered catalyst from the experiment was washed by acetone $(3 \times 5 \mathrm{~mL})$. Then, it was dried in an oven at $100^{\circ} \mathrm{C}$ and used in the synthesis of 1,4dihydropyridines. Then the catalyst was recycled for five times.

\subsection{Selected spectral data}

2.4a Diethyl 4-(4-bromophenyl)-2,6-dimethyl-1,4-dihydropyridine-3,5-dicarboxylate (4f): ${ }^{1} \mathrm{H}$ NMR $(400 \mathrm{MHz}$, $\left.\mathrm{CDCl}_{3}\right): \delta=1.23\left(\mathrm{t}, 6 \mathrm{H}, 2 \mathrm{CH}_{3} \mathrm{CH}_{2}\right), 2.31(\mathrm{~s}, 6 \mathrm{H}$, 


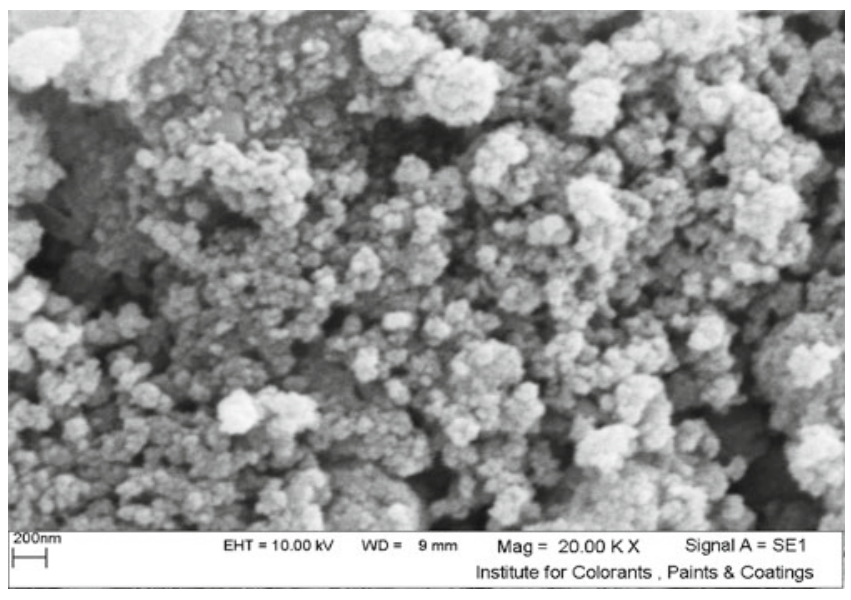

Figure 2. SEM image of the $\mathrm{FeCl}_{3} / \mathrm{SiO}_{2} \mathrm{NPs}$.

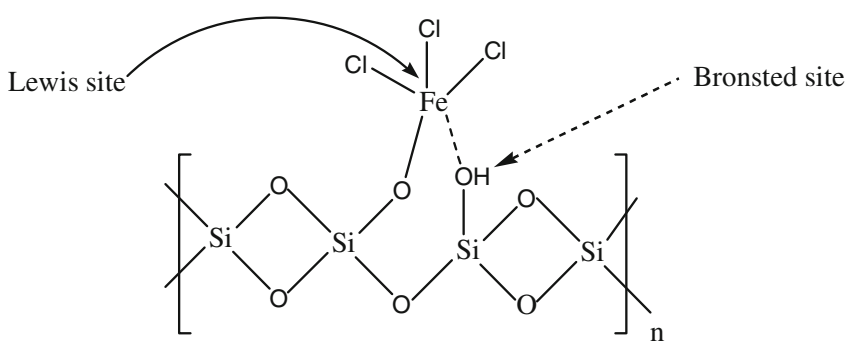

Scheme 2. Bronsted acidity arising from inductive effect of Lewis acid center coordinated to nanosilica support.

$\left.2 \mathrm{CH}_{3}\right), 4.09$ (q, $\left.4 \mathrm{H}, 2 \mathrm{CH}_{3} \mathrm{CH}_{2}\right), 4.94(\mathrm{~s}, 1 \mathrm{H}, \mathrm{CH}), 5.82$ (s, 1H, NH), 7.16 (d, 2H, 2CHarom.), 7.33 (d, 2H, 2CHarom.). ${ }^{13} \mathrm{C}$ NMR (100 MHz, $\left.\mathrm{CDCl}_{3}\right): \delta=14.2$,
$19.4,39.3,59.8,103.4,119.8,129.8,130.8,144.3$, 146.9, 167.5. FT-IR (KBr): 3355, 1696, 1651, 1487, $1213,1092,783 \mathrm{~cm}^{-1}$.

2.4b Diethyl 4-(4-Nitrophenyl)-2,6-dimethyl-1,4-dihydropyridine-3,5-dicarboxylate (4b): ${ }^{1} \mathrm{H}$ NMR $(400 \mathrm{MHz}$, $\left.\mathrm{CDCl}_{3}\right): \delta=1.23\left(\mathrm{t}, 6 \mathrm{H}, 2 \mathrm{CH}_{3} \mathrm{CH}_{2}\right), 2.36(\mathrm{~s}, 6 \mathrm{H}$, $\left.2 \mathrm{CH}_{3}\right), 4.09$ (q, $\left.4 \mathrm{H}, 2 \mathrm{CH}_{3} \mathrm{CH}_{2}\right), 5.09(\mathrm{~s}, 1 \mathrm{H}, \mathrm{CH}), 5.72$ (s, 1H, NH), 7.26 (d, 2H, 2CHarom.), 8.09 (d, 2H, 2CHarom.). ${ }^{13} \mathrm{C}$ NMR (100 MHz, $\mathrm{CDCl}_{3}$ ): $\delta=14.2$, $19.4,39.3,59.8,103.4,119.8,130.0,130.8,144.3$, 146.9, 167.5. FT-IR (KBr): 3343, 1706, 1646, 1486, $1212,1115,786 \mathrm{~cm}^{-1}$.

2.4c Diethyl 4-(2-thienyl)-2,6-dimethyl-1,4-dihydro-pyridine-3,5-dicarboxylate $(4 m):{ }^{1} \mathrm{H} \quad \mathrm{NMR} \quad(400 \quad \mathrm{MHz}$, $\left.\mathrm{CDCl}_{3}\right): \delta=1.24\left(\mathrm{t}, 6 \mathrm{H}, 2 \mathrm{CH}_{3} \mathrm{CH}_{2}\right), 2.31(\mathrm{~s}, 6 \mathrm{H}$, $2 \mathrm{CH}_{3}$ ), 4.09 (q, $4 \mathrm{H}, 2 \mathrm{CH}_{3} \mathrm{CH}_{2}$ ), 4.99 (s, $1 \mathrm{H}, \mathrm{CH}$ ), 5.88 (s, 1H, NH), 7.12 (d, 1H, 1CHarom.), 7.20 (d, 1H, 1CHarom.), 7.29 (d, 1H, 1CHarom.). ${ }^{13} \mathrm{C}$ NMR $\left(100 \mathrm{MHz}, \mathrm{CDCl}_{3}\right): \delta=14.2,19.3,39.6,59.7,103.8$, 126.1, 127.8, 144.3, 147.8, 167.8. FT-IR (KBr): 3358, $1686,1641,1487,1215,1082,773 \mathrm{~cm}^{-1}$.

\section{Results and discussions}

We report here a simple and convenient method for the synthesis of 1,4-dihydropyridines by condensation of aldehydes with ethyl acetoacetate and ammonium<smiles>CCOC(=O)C(=C[Al])C(C)=O</smiles>

(I)

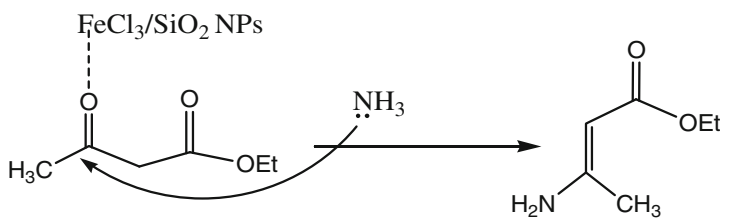

(II)<smiles>CCOC(=O)C1=C(C)NC(C)=C(C(=O)OCC)C1Br</smiles>

(III)

Scheme 3. The proposed mechanism of the synthesis of 1,4-dihydropyridines in the presence of silica (NPs) supported Fe (III). 
Table 2. Preparation of 1,4-dihydropyridines in the presence of silica (NPs) supported Fe (III) in different solvents.

\begin{tabular}{llcc}
\hline Entry & \multicolumn{1}{c}{ Solvent } & Time (min) & Yield, ${ }^{\mathrm{a}} \%$ \\
\hline 1 & $\mathrm{CH}_{3} \mathrm{CN}$ & 70 & 37 \\
2 & Toluene & 90 & 31 \\
3 & $\mathrm{H}_{2} \mathrm{O}$ & 90 & 49 \\
4 & EtOH & 20 & 94 \\
5 & EtOH/ $\mathrm{H}_{2} \mathrm{O}$ & 60 & 73 \\
6 & Solvent-free & 75 & 29 \\
\hline
\end{tabular}

${ }^{\mathrm{a}}$ Isolated yield

Table 3. The catalyst reusability for the synthesis of 1,4dihydropyridines.

\begin{tabular}{lcc}
\hline Entry & Cycle & Yield, ${ }^{\mathrm{a} \%}$ \\
\hline 1 & Fresh & 94 \\
2 & 1 & 94 \\
3 & 2 & 94 \\
4 & 3 & 93 \\
5 & 4 & 93 \\
6 & 5 & 93 \\
\hline
\end{tabular}

asolated yield

acetate in ethanol at reflux conditions in the presence of silica (NPs) supported Fe (III). Silica (NPs) supported Fe (III) is an inexpensive heterogeneous reagent, which can be prepared easily by treating ferric chloride with silica nanoparticle. Ease and safety in handling, rate enhancement, high yields and easy work up procedures for reuse are the properties which made us to use this interesting reagent as a catalyst. To the best of our knowledge there are no reports on the applicability of silica (NPs) supported Fe (III) for the synthesis of 1,4-dihydropyridines in the literature.

In the preliminary experiments, the catalytic behaviours of five types of catalyst were compared in the reaction of $p$-nitrobenzaldehyde, ethyl acetoacetate and ammonium acetate at reflux conditions (table 1).

In the absence of catalyst, the reaction did not progress at all. Notably, silica (NPs) supported Fe (III) shows an activity higher than those reported in heterogeneous, we believe that nano silica surface chemistry plays an important role in this reaction.

To obtain a visual image of the supported catalyst, scanning electron microscopy (SEM) was carried out. By SEM image some information about the morphology of the catalyst particles was obtained as presented in figure 2. The SEM image shows particles with diameters in the range of nanometers to micrometers. As indicated in figure 2, the gray particles is nano silica which are supported by $\mathrm{FeCl}_{3}$ white particles.

Silica (NPs) supported Fe (III) can act as Bronsted and Lewis acid catalysts, ${ }^{28}$ as illustrated in scheme 2 .

The effect of catalyst and its abilities to act as a Brønsted or Lewis acid (empty $\pi$ orbital of Fe in silica (NPs) supported Fe (III)) is suggested in scheme 3. In this mechanism, we propose that an acid-base interaction between silica (NPs) supported Fe (III) and loan pair of oxygen polarizes $\mathrm{C}=\mathrm{O}$ bond of aldehyde. Then knovenagel product (I) and ester enamine (II) were prepared by this interaction. Condensation of these two fragments gives intermediate (III) which subsequently cyclizes to the 1,4-dihydropyridine. ${ }^{29}$

Table 4. Silica (NPs) supported Fe (III) catalysed synthesis of 1,4-dihydropyridines 4a-n.

Entry Time (min)


Table 4. (continued)

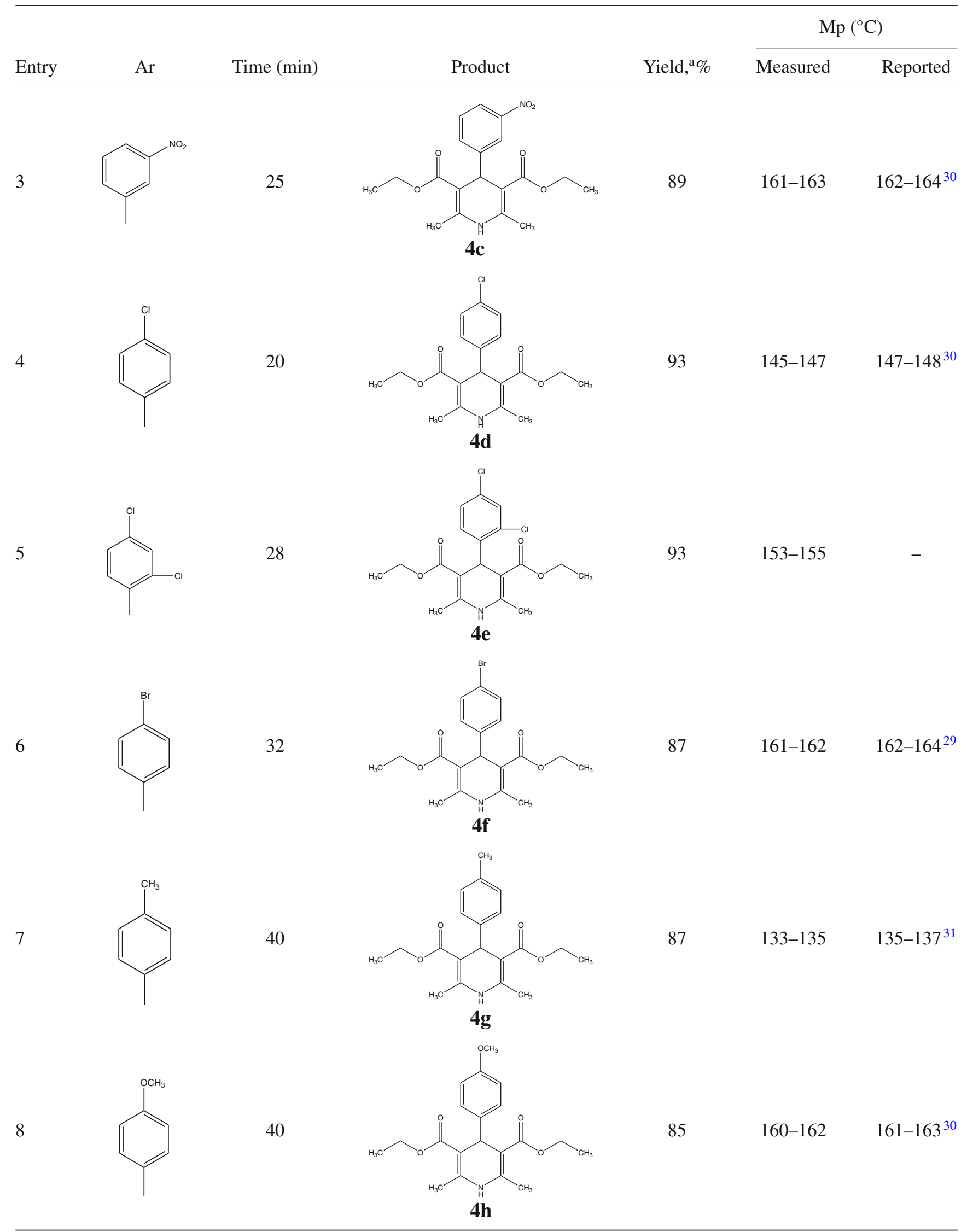


Table 4. (continued)

\begin{tabular}{|c|c|c|c|c|c|c|}
\hline \multirow[b]{2}{*}{ Entry } & \multirow[b]{2}{*}{$\mathrm{Ar}$} & \multirow[b]{2}{*}{ Time (min) } & \multirow[b]{2}{*}{ Product } & \multirow[b]{2}{*}{ Yield, ${ }^{\mathrm{a}} \%$} & \multicolumn{2}{|c|}{$\mathrm{Mp}\left({ }^{\circ} \mathrm{C}\right)$} \\
\hline & & & & & Measured & Reported \\
\hline 9 & & 35 & & 89 & $156-158$ & $150-152^{32}$ \\
\hline 10 & & 25 & & 86 & $147-149$ & - \\
\hline 11 & & 27 & & 91 & $160-162$ & $160-161^{31}$ \\
\hline 12 & & 33 & & 91 & $170-172$ & $171-173^{31}$ \\
\hline 13 & & 26 & & 90 & $166-168$ & - \\
\hline
\end{tabular}

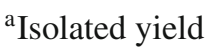

Expectedly, the catalytic system should be influenced by various reaction parameters, such as amount of the employed catalyst and solvent system. To establish the optimal reaction conditions, a set of experiments varying the amount of silica (NPs) supported Fe (III), and effect of solvent were taken into account.

We have screened effect of different solvents with varying polarity and protic nature. It was observed that ethanol proved to be the best choice for this reaction over any organic solvents such as acetonitrile and toluene. Also, it was observed that the good results were not obtained in solvent-free conditions. The results are presented in (table 2).

First, we optimized the amount of silica (NPs) supported Fe (III) as catalyst in the model reaction. The optimum amount of silica (NPs) supported Fe (III) was chosen to be $0.6 \mathrm{~mol} \%$. The same reaction was carried out five times consequently to check the reusability of catalyst and it was found that, all the five times, it gave almost the same yield of product without significant decrease in activity (table 3 ). 
The study was then extended to preparation of various 1,4-dihydropyridines using silica (NPs) supported $\mathrm{Fe}$ (III) in high yields. Reactions were carried out in ethanol at reflux conditions. The results are listed in table 4.

\section{Conclusion}

In conclusion, it was demonstrated that a novel readily available, economic silica (NPs) supported Fe (III) has been prepared. This catalyst could behave as recyclable and heterogeneous solid acid for the synthesis of various substituted 1,4-dihydropyridines. The condensation of aldehydes with ethyl acetoacetate and ammonium acetate in ethanol afforded 1,4-dihydropyridines, offering the practical convenience in the product separation from the catalytic system. The merit of this methodology is that it is simple, fast, mild and efficient.

\section{Acknowledgements}

The authors are thankful to University of Kashan for supporting this work by Grant NO: 65384. Also, authors thank Prof. Stephen G Pyne and Dr Abdolhamid Bamoniri for their help.

\section{References}

1. Triggle D J, Langs D D, and Janis R A 1989 Med. Res. Rev. 9123

2. Godfraind T, and Salomone S J 1997 Cardiovasc. Pharmacol. 30289

3. Van Zwieten P A 1998 Blood Press. 15

4. Nayler W G 1999 J. Clin. Basic Cardiol. 2155

5. Janis R A, and Triggle D J 1983 J. Med. Chem. 25775

6. Sausins A, and Duburs G 1988 Heterocycles 27269

7. Bretzel R G, Bollen C C, Maeser E, and Fedrlin K F 1992 Am. J. Kidney Dis. 17465
8. Sridhar R, and Perumal P T 2005 Tetrahedron 612465

9. Heravi M M, Behbahani F K, Oskooie H A, and Shoar R H 2005 Tetrahedron Lett. 462775

10. Buhler F R, and Kiowski W J 1987 Hypertens. 5 S3

11. Alajarin R, Vaquero J J, Garcia Navio J L, and AlvarezBuilla J 1992 Synlett. 4297

12. Sausins A, and Duburs G 1988 Heterocycles 27269

13. Agarwal A, and Chauhan P M S 2005 Tetrahedron Lett. 461345

14. Ji S J, Jiang Z Q, Lu J, and Loh T P 2004 Synlett. 5831

15. Dondoni A, Massi A, Minghini E, Bertoasi V 2004 Tetrahedron 602311

16. Sabitha G, Reddy G S K K, Reddy C S, and Yadav J S 2003 Tetrahedron Lett. 444129

17. Babu G, and Perumal P T 2000 Aldrichim. Acta 1633

18. Ko S, Sastry M N V, Lin C, and Yao C F 2005 Tetrahedron Lett. 465771

19. Adharvana Chari M, and Syamasundar K 2005 Catal. Commun. 6624

20. Maheswara M, Siddaiah V, Rao Y K, Tzeng Y M, and Sridhar C 2006 J. Mol. Catal. 260179

21. Ko S, and Yao C F 2006 Tetrahedron 627293

22. Perozo-Rondon E, Calvino-Casilda V, Martin-Aranda R M, Casal B, Duran- Valle C J, and Rojas-Cervantes M L 2006 Appl. Surf. Sci. 2526080

23. Tewari N, Dwivedi N, and Tripathi R P 2004 Tetrahedron Lett. 459011

24. Lee J H 2005 Tetrahedron Lett. 467329

25. Kumar A, and Maurya R A 2007 Tetrahedron 631946

26. Wang L M, Sheng J, Zhang L, Han J W, Fan Z, Tian H, and Qian C T 2005 Tetrahedron 611539

27. Hantzsch A 1882 Justus Liebigs Ann. Chem. 1215

28. Wilson K, and Clark J H 2000 Pure Appl. Chem. 72 1313

29. Debache A, Ghalem W, Boulcina R, Belfaitah A, Rhouati S, and Carboni B 2009 Tetrahedron Lett. 50 5248

30. Eynde J J, Delfosse F, and Mayence A 1995 Tetrahedron 516511

31. Khadikar B M, Gaikar V G, and Chitnavis A A 1995 Tetrahedron Lett. 368083

32. Love B, Goodman M M, and Snader K M 1974 Eur. J. Med. Chem. 1777 